\title{
Synthesis and Crystal Structure of Anickel (II) and Zinc (II) Complex From 1,5-Bis [(2-Thiophenyl) Methylidene] Thiocarbonohydrazide
}

\author{
DjibyLO $^{\mathrm{a}}$, MahyDIAW ${ }^{\mathrm{a}}$, Papa Aly GAYE ${ }^{\mathrm{a}}$, Moussa DIENG ${ }^{\mathrm{a}}$, \\ OusmaneDIOUF ${ }^{\mathrm{a}}$, Aliou Hamady BARRY ${ }^{\mathrm{b}}$, Abdou Salam SALL ${ }^{\mathrm{a}}$, Mohamed \\ GAYE ${ }^{\mathrm{a}, 1}$ \\ ${ }^{a}$ Department of Chemistry, University Cheikh Anta Diop, Dakar, Sénégal \\ ${ }^{b}$ Department of Chemistry, University of Nouakchott, Nouakchott, Mauritania
}

\begin{abstract}
The title mononuclear nickel and zinc complexes, $\mathrm{Ni}\left(\mathrm{C}_{11} \mathrm{H}_{9} \mathrm{~N}_{4} \mathrm{~S}_{3}\right)_{2}$ and $\mathrm{Zn}\left(\mathrm{C}_{11} \mathrm{H}_{9} \mathrm{~N}_{4} \mathrm{~S}_{3}\right)_{2} \cdot 2\left(\mathrm{C}_{3} \mathrm{H}_{7} \mathrm{NO}\right)$, were prepared by the reaction of Nickel(II) or Zinc(II)acetate with 1,5-bis[(2thiophenyl)methylidene]thiocarbonohydrazide in a methanol solution. It features mono-deprotonated bisbidentate ligands, which coordinate to metal (II) ions by hydrazylN and thiocarbony lS atoms, yielding a tetracoordinated metal ions complexes. In Ni(II) complex the geometry around the metal ion is described as square planar. In the Zn(II) the metal atom shows severely tetrahedral distortion from anideal square-planar coordination geometry, as reflected by the dihedral angle between $\mathrm{ZnN}_{2}$ and $\mathrm{ZnS}_{2}$ planes of $73.03(13)^{\circ}$. Two intramolecular hydrogen bonds are observed between the solvate dmf molecules and the coordinated ligands: $N 2-H 2 N \cdots \mathrm{Ol}^{i}$ and $\mathrm{N} 6-\mathrm{H} 6 \mathrm{~N} \cdots \mathrm{O} 2^{i i}$ in this complex.
\end{abstract}

Keywords: Schiff base, Thiocarbonyl, Nickel, Zinc, tetrahedral, Electrochemistry.

\section{Introduction}

Organic molecules containing thiohydrazone moieties are interest compounds useful to study the bonding of metal ions to synthesize inorganic complexes [1-3] which have found utility in a wide range of applications [4-6]. Schiff bases issued from keto-precursor and hydrazone have been largely investigated owing to their capacity to append various substituants $[7,8]$. Because of the capability to provide various modes of coordination, this chemistry is able to generate stable structures $[9,10]$. The combination of versality of the binding modes and the nature of the metal ion is expected to generate new compound. These ligands may design to yield special topological structures. The molecular design can be modulated to link in different manners metal ions resulting in original architectures. In the course of our studies on the chemistry of transition metal compounds, we have prepared and characterized a number of chelates containing $\mathrm{N}$ and $\mathrm{O}$ donor sites [11-15]. Considerable interest is accorded to the development of multidentate ligands containing different binding sites such as $\mathrm{N}, \mathrm{O}$ or $\mathrm{S}[16,17]$. Herein we present a structurally characterized nickel(II) and zinc(II) complexes synthesized from potentially heptadentate Schiff base ligand.

\subsection{Material and measurements}

\section{Experimental Section}

Thiocarbonohydrazide, 2-thiophenecarboxaldehyde and metal salts were commercial products of highest chemical grade (Aldrich). Solvents were purified according to standard procedures. Elemental analysis of $\mathrm{C}, \mathrm{H}$ and $\mathrm{N}$ was performed by the analytical laboratory of the Department of Inorganic Chemistry (University of Padua, Italy). FTIR spectra were recorded with a Nicolet 5SXC FT-IR spectrophotometer using KBr pellets. Molar conductance measurement was made using a WTW LF-330 conductivity meter with a WTW conductivity cell on about $1 \mathrm{mmol} \mathrm{dm}$ dimethylformamide solution at room temperature. Room temperature magnetic susceptibility measurements were made on solid complex using a Johnson-Mathey Gouy balance with $\mathrm{Hg}\left[\mathrm{Co}(\mathrm{SCN})_{4}\right]$ as the calibrator. Electrochemical measurements were performed with a BAS CV 27 voltammogram and a BAS A-4 XY register using a graphite carbon $(\phi 5 \mathrm{~mm})$ working electrode, a platinum wire as auxiliary and a double junction, with porous ceramic wick, $\mathrm{Ag} / \mathrm{AgCl}$ reference electrode, standardized for the redox couple ferricinium/ferrocene $(\mathrm{E} 1 / 2=0.400 \mathrm{~V}, \Delta \mathrm{Ep}=60 \mathrm{mV})$. Cyclic voltammetry studies of ligands and complex were carried out on $0.01 \mathrm{M}$ solutions in dimethylformamide containing $0.1 \mathrm{M}\left[\mathrm{NBu}_{4}\right]\left[\mathrm{PF}_{6}\right]$ (tetrabutylammoniumhexafluorophosphate: TBAHFP) as supporting electrolyte. The range of potential studied

${ }^{1}$ Corresponding author :mohamedl.gaye@ucad.edu.sn 
was between +1 and $-1.5 \mathrm{~V}$. The solution was purged with nitrogen steam for 5 min before measurement and the working electrode was polished before experiment with diamond paste. The procedure was performed at room temperature and a nitrogen atmosphere was maintained over the solution during the measurements.

\subsection{X-ray data collection, structure determination, and refinement}

Slow evaporation of dmf solution gave X-ray quality crystals of the compound. The details of the X-ray crystal structures solution and refinement are given in Table I. The details of the X-ray crystal data, structure solution and refinement are given in Table 1. Diffraction data were collected using a CAD4 EXPRESS diffractometer with graphite monochromatized Mo K $\alpha$ radiation $(\lambda=0.71073 \AA$ ). All data were corrected for Lorentz and polarization effects and for absorption by semi empirical methods based on symmetry-equivalent and repeated reflections. Complex scattering factors were taken from the program package SHELXTL [18]. The structures were solved by direct methods which revealed the position of all non-hydrogen atoms. All the structures were refined on $F^{2}$ by a full-matrix least-squares procedure using anisotropic displacement parameters for all non hydrogen atoms [19]. The hydrogen atoms were located in their calculated positions and refined using a riding model. Molecular graphics were generated using ORTEP-3 [20].

Table-1. Crystallographic data and refinement parameters for (1) and (2).

\begin{tabular}{|c|c|c|}
\hline Compound & $\mathrm{Ni}(\mathrm{HL})_{2}$ & $\mathrm{Zn}(\mathrm{HL})_{2} \cdot 2 \mathrm{DMF}$ \\
\hline Formula of refinement & $\mathrm{C}_{22} \mathrm{H}_{18} \mathrm{~N}_{8} \mathrm{~S}_{6} \mathrm{Ni}$ & $\mathrm{C}_{22} \mathrm{H}_{18} \mathrm{~N}_{8} \mathrm{~S}_{6} \mathrm{Zn} \cdot 2\left(\mathrm{C}_{3} \mathrm{H}_{7} \mathrm{NO}\right)$ \\
\hline Molecular weight (g/mol) & 645.51 & 798.37 \\
\hline Crystal system & Orthorhombic & Monoclinic \\
\hline Space group & Pbca & $\mathrm{P} 2_{1}$ \\
\hline$a(\AA)$ & $11.719(1)$ & $12.1802(9)$ \\
\hline$b(\AA)$ & $9.040(1)$ & $9.7488(7)$ \\
\hline$c(\AA)$ & $25.788(1)$ & $16.8456(12)$ \\
\hline$\beta\left(^{\circ}\right)$ & 90 & $109.181(1)$ \\
\hline$V\left(\AA^{3}\right)$ & $2732(2)$ & $1889.2(2)$ \\
\hline$D_{\mathrm{c}}\left(\mathrm{g} \mathrm{cm}^{-3}\right)$ & 1.569 & 1.403 \\
\hline$Z$ & 4 & 2 \\
\hline Crystal size (mm) & $0.30 \times 0.30 \times 0.06$ & $0.35 \times 0.15 \times 0.10$ \\
\hline Crystal colour & yellow & yellow \\
\hline Crystal habit & square plate & prismatic \\
\hline $\operatorname{Mo~}_{\alpha}(\AA)$ & 0.71073 & 0.71073 \\
\hline$\mu\left(\mathrm{mm}^{-1}\right)$ & 1.20 & 1.02 \\
\hline$T(K)$ & $293(2)$ & $293(2)$ \\
\hline $2 \theta_{\max }$ & 25.24 & 25.02 \\
\hline hklrange & $-14,14 ; \quad-10,10 ; \quad-30,30$ & $-14,14 ;-11,11 ; \quad-20,20$ \\
\hline Measuredreflections & 16273 & 14527 \\
\hline Independent reflections & 2490 & 3541 \\
\hline Reflections with $\mathrm{I}>2 \sigma(\mathrm{I})$ & 1650 & 2747 \\
\hline Parameters & 172 & 430 \\
\hline Restraints & 1 & 3 \\
\hline$R_{\text {int }}$ & 0.045 & 0.048 \\
\hline$R_{1}(F)[\mathrm{I}>2 \sigma(\mathrm{I})]$ & 0.042 & 0.036 \\
\hline$w R_{2}\left(F^{2}\right)$ & 0.115 & 0.102 \\
\hline Goodness-of-fit & 0.999 & 1.06 \\
\hline$\Delta \rho_{\min , \max }\left(\AA^{3}\right)$ & $-0.37,0.54$ & $-0.31,0.35$ \\
\hline
\end{tabular}

\subsection{Synthesis of ligand $\left(\mathrm{H}_{2} \mathrm{~L}\right)$}

To a $50 \mathrm{~mL}$ round bottom flask thiocarbonohydrazide $(2.12 \mathrm{~g}, 0.020 \mathrm{~mol})$ dissolved in methanol (10 $\mathrm{mL})$ and 2-thiophenecarboxaldehyde $(4.49 \mathrm{~g}, 0.040 \mathrm{~mol})$ inmethanol $(10 \mathrm{~mL})$ were added to yield immediately and quantitatively a whiteprecipitate. The precipitate was separated by filtration, washed with methanol and ether and dried under vacuum. The compound is insoluble in common organic solvent. Yield $4.15 \mathrm{~g}, 70.5 \%$; m.p. 482 K. IR data $\left(\mathrm{cm}^{-1}\right) 3448,1592,1540,1505,1259,1227$ and 710 . Anal.Calc. for $\mathrm{C}_{11} \mathrm{H}_{10} \mathrm{~N}_{4} \mathrm{~S}_{3}(\%): \mathrm{C}$, 44.87; H, 3.42; N, 19.03; S, 32.67. Found: C, 44.85; H, 3.40; N, 19.07; S, 32.69.Mass spectrum (m/z, 294).

\subsection{Synthesis of $\left[\mathrm{Ni}(\mathrm{HL})_{2}\right](1)$}

Methanolic solution $(5 \mathrm{~mL})$ of nickel acetate tetrahydrate $(0.3111 \mathrm{~g}, 1.25 \mathrm{mmol})$ was added to a methanolicsuspension $(10 \mathrm{~mL})$ of the ligand prepared above $(0.6958 \mathrm{~g}, 2.5 \mathrm{mmol})$. The resulting mixture was refluxed for two days. The green solution was filtered and then allowed to evaporate slowly. The resulting powder was recrystallized from dimethylformamide solution. After one week, yellow powder was obtained. The powder was separated and dried in air. The resulting powder was recrystallized again from dimethylformamide solution. After one week, yellow crystals suitable for X-ray analysis were obtained (yield: 75\%); Anal. Calc. for 
$\mathrm{C}_{22} \mathrm{H}_{18} \mathrm{NiN}_{8} \mathrm{~S}_{6}(\%)$ : C, 40.93; H, 2.81; N, 17.36; S, 29.80. Found: C, 40.81; H, 2.71; N, 16.85; S, 28.99. Selected IR data $\left(\mathrm{cm}^{-1}\right.$, in $\mathrm{KBr}$ pellet): $1575,1562,1512,1429,1366$ and $1210 . \mu_{\mathrm{eff}}=$ diamagnetic.

\subsection{Synthesis of $\left[\mathrm{Zn}(\mathrm{HL})_{2}\right] \cdot 2 \mathrm{DMF}(2)$}

Methanolic solution $(5 \mathrm{~mL})$ of zinc acetate dihydrate $(0.2744 \mathrm{~g}, 1.25 \mathrm{mmol})$ was added to a me than olicsuspension $(10 \mathrm{~mL})$ of the ligand prepared above $(0.6958 \mathrm{~g}, 2.5 \mathrm{mmol})$. Theresulting mixture was refluxed for one day. The yellow solution was filteredand then allowed to evaporate slowly. The resulting powder was recrystallizedfrom dimethylformamide solution. After one week, yellow crystals suitable forX-ray analysis were obtained. The crystals were separated and dried in air(yield: 65\%); Anal. Calc. for $\mathrm{C}_{28} \mathrm{H}_{32} \mathrm{ZnN}_{10} \mathrm{O}_{2} \mathrm{~S}_{6}$ (\%): C, 42.12; H,4.04; N, 17.54; S, 24.10. Found: C, 42.14; H, 4.06; N, 17.50; S, 24.12.Selected IR data $\left(\mathrm{cm}^{-1}\right.$, in KBrpellet): 3314, 3100, 1575, 1559, 1504 and 1240.Paramagnetic.

\subsection{Spectroscopic studies}

\section{Resultsand Discussion}

The results of the elemental analysis are in good agreement with the calculated values. The mononuclear complexes are stable in air, non-hygroscopic, insoluble in water but are easily soluble in methanol and DMF. The electrolytic nature of the complexes was measured in DMF at $10^{-3} \mathrm{M}$. The molar conductivities $\Lambda$ are $4.1 \Omega^{-1} \mathrm{~cm}^{2} \mathrm{~mol}^{-1}$ for $\mathrm{Ni}(\mathrm{II})$ complex and $1,3 \Omega^{-1} \mathrm{~cm}^{2} \mathrm{~mol}^{-1}$ for $\mathrm{Zn}$ (II) confirming that they are nonelectrolytic in DMF solutions [21]. In the solid-state IR spectrum of the ligand $\mathrm{H}_{2} \mathrm{~L}$, characteristic band of ligand observed at $1575 \mathrm{~cm}^{-1}$ is assigned to the conjugated $\mathrm{C}=\mathrm{N}$ vibration band. Bands in the region $3300-3100 \mathrm{~cm}^{-1}$ are attributed to the $v(\mathrm{~N}-\mathrm{H})$ vibrations of the hydrazide moieties. The band at $1210 \mathrm{~cm}^{-1}$ is assignable to the thione $\mathrm{C}=\mathrm{S}$ function. Upon coordination, the solid-state IR spectra of the complexes were compared with that of the ligand. It was found that $\mathrm{C}=\mathrm{N}$ bands vibration in these complexes are 1575 and $1562 \mathrm{~cm}^{-1}$ for $\mathrm{Ni}$ (II) complex and1575 and $1559 \mathrm{~cm}^{-1}$ for $\mathrm{Zn}$ (II)complex. The presence of the first band at $1575 \mathrm{~cm}^{-1}$ show that one of the azomethine is not coordinated to the metal center. The presence of the new second bands showing a shift to lower frequencies is indicative of the involvement of one of the nitrogen atom of azomethine $(\mathrm{CH}=\mathrm{N})$ groups in Metal-Nitrogen bond formation. The remaining of bands in the region $3300-3100 \mathrm{~cm}^{-1} v(\mathrm{~N}-\mathrm{H})$, the absence of a band at $1210 \mathrm{~cm}^{-1} v(\mathrm{C}=\mathrm{S})$ combined to the apparition of a band near $710 \mathrm{~cm}^{-1} v(\mathrm{C}-\mathrm{S})$ indicates evidence for ligand coordination to the metal ions in its monodeprotonated form. The solid state UV-Vis spectrum of the ligand HL shows two absorption bands at 294-296 and 328-334 nm due to $\pi \rightarrow \pi^{*}$ transitions of the aromatic rings and $\mathrm{n} \rightarrow \pi^{*}$ transitions of the $\mathrm{C}=\mathrm{N}$ groups. The $\mathrm{UV}-\mathrm{Vis}$ spectrum was recorded in methanol solution in the range of $260-800 \mathrm{~nm}$ for nickel(II) complex.LMCT bandsobserved at $424 \mathrm{~nm}$ and $450 \mathrm{~nm}$ can be assigned respectively to $\mathrm{N} \rightarrow \mathrm{Ni}$ and $\mathrm{S} \rightarrow$ Nicharge transfer. The high intensity charge transfer (CT) band $\mathrm{S} \rightarrow$ Nihide some of the three expected transitions corresponding to ${ }^{1} \mathrm{~A}_{1 \mathrm{~g}} \rightarrow{ }^{1} \mathrm{~A}_{2 \mathrm{~g}},{ }^{1} \mathrm{~A}_{1 \mathrm{~g}} \rightarrow{ }^{1} \mathrm{~B}_{1 \mathrm{~g}}$ and ${ }^{1} \mathrm{~A}_{1 \mathrm{~g}} \rightarrow{ }^{1} \mathrm{E}_{\mathrm{g}}$ for square planar Ni(II) complex[22].Only a weak broad band in the $520-600 \mathrm{~nm}$ region is attributed to the square planar Nickel(II) $\mathrm{d}-\mathrm{d}$ transition. These observations coupled to X-ray crystal structure analysis support a square-planar geometry for the nickel(II) complex.

\subsection{Electrochemistry study}

The electrochemical properties of the $\mathrm{Ni}(\mathrm{II})$ complex was examined by cyclic voltammeter using a graphite carbon working electrode and a Pt-wire auxiliary electrode in dry dimethylformamide using $0.1 \mathrm{M}$ [n$\left.\mathrm{Bu}_{4} \mathrm{~N}\right] \cdot \mathrm{ClO}_{4}$ as the supporting electrolyte. The voltammetric parameters were studied in the scan rate interval $100-180 \mathrm{mV} \mathrm{s}^{-1}$. In Figure 1, curve (a) describes the electrochemical behavior of the free ligand in DMF medium. We note one oxidation and one reduction pics $\left(E p a_{1}, E p c_{l}\right)$. The electro activity field is limited by the solvent's walls of oxidation and reduction. Curve (b) shows the electrochemical behavior of the Ni complex. Two new peaks $\left(E p a_{2}, E p c_{2}\right)$, which are attributed to oxidation and reduction peaks of $\mathrm{Ni}$ complex with the organic ligand are revealed.

The ligand showed one irreversible oxidation at $E p a_{l}=1.14 \mathrm{~V}$ and one irreversible reduction at $E p c_{l}=$ $-1.45 \mathrm{~V}$ versus $\mathrm{Ag} / \mathrm{AgCl}$ in the scan rate of $0.10 \mathrm{Vs}^{-1}$. The complex $\left[\mathrm{Ni}(\mathrm{HL})_{2}\right]$ exhibited one anodic wave at $\mathrm{Epa} 2=1.66 \mathrm{~V}$ with corresponding one cathodic wave $E p c_{2}=-1.1 \mathrm{~V}$. The anodic wave is assigned to the oxidation of $\left[\mathrm{Ni}(\mathrm{HL})_{2}\right]$ complex $\mathrm{Ni}^{\mathrm{II}} / \mathrm{Ni}^{\mathrm{III}}$ while the corresponding cathodic peak wave is attributed to the reduction process of the $\left[\mathrm{Ni}(\mathrm{HL})_{2}\right]$ complex $\mathrm{Ni}^{3+} \stackrel{+\mathrm{e}^{-}}{\longrightarrow} \mathrm{Ni}^{2+}$ which appears at different position of Epc1 of the ligand reduction process. A cathodic response recommended for reduction $\mathrm{Ni}^{\mathrm{III}} / \mathrm{Ni}^{\mathrm{II}}$ is observed at $-1.10 \mathrm{~V}$ versus $\mathrm{Ag} / \mathrm{AgCl}$ (Figure 2). Those facts are indicative that the oxidation and reduction processes of the complex are not based on the ligand. Changes in peak intensities $E p a_{1}, E p a_{2}$ and $E p c_{2}$ depending on the potential scan rate $(\log \mathrm{Ip}=\mathrm{f}(\log \mathrm{V}))$ are shown in Figure 3. In the range $100-180 \mathrm{mV} / \mathrm{s}$ the dependency of Epa $a_{l}$ peak is linear and the slope of the straight line $(0.48)$ is close proximity of 0.5 which is indicative that the electrochemical behavior of the ligand is limited by diffusion. Epa 2 and $E p c_{2}$ are also a linear dependence but the recorded 
slopes ( 0.42 and 0.44 respectively) are not indicative of electrochemical reaction kinetics controlled by diffusion phenomena [23].

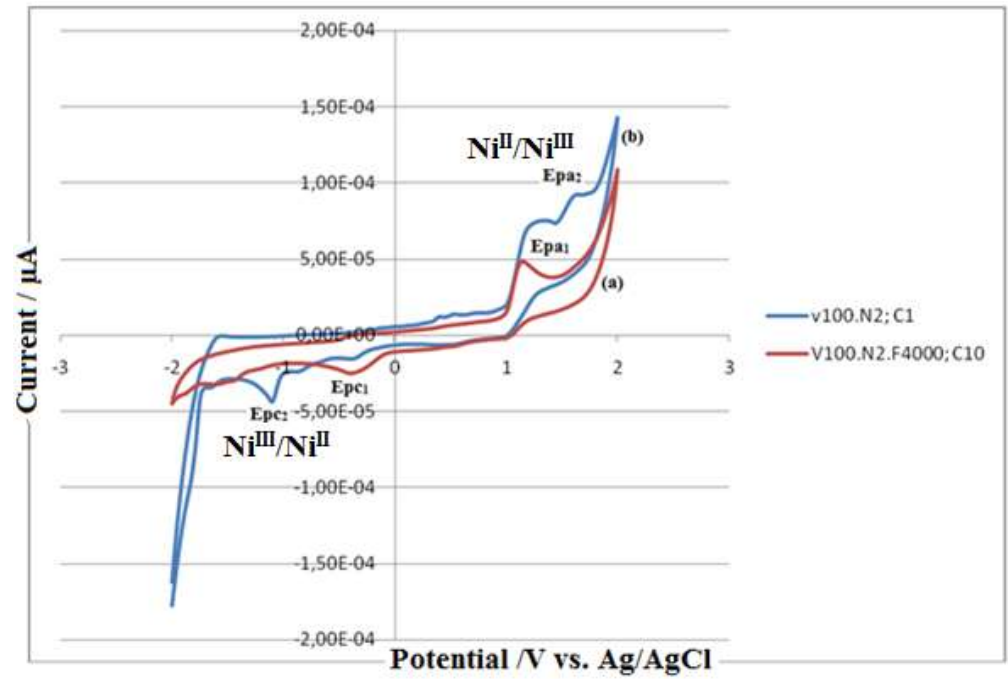

Figure 1: Cyclic Votammograms of the complex (blue) and the ligand (red) in DMF containing $0.1 \mathrm{M}$

$\left[\mathrm{NBu}_{4}\right]\left[\mathrm{PF}_{6}\right]$. Scan rate: $100 \mathrm{mV}$. Working electrode: a $5 \mathrm{~mm}$ diameter of graphite carbon electrode.

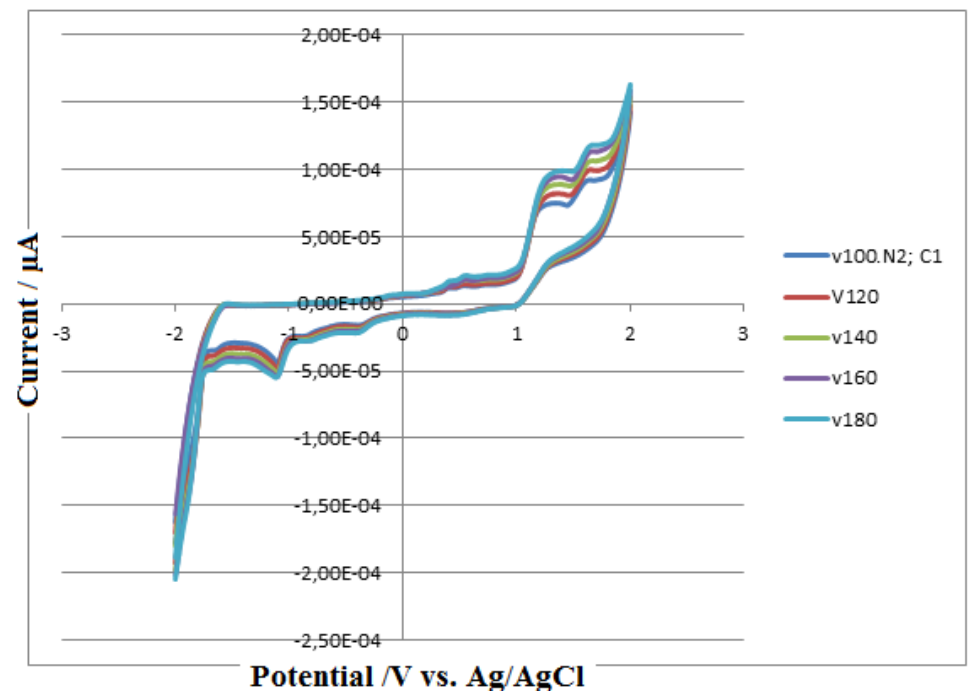

Figure 2: Cyclic Votammograms of the complex in DMF containing 0.1 M [NBu 4$]\left[\mathrm{PF}_{6}\right]$. Scan rate: 100,120 , 140180 and $200 \mathrm{~m}$ V.Working electrode: a $5 \mathrm{~mm}$ diameter of graphite carbon electrode.

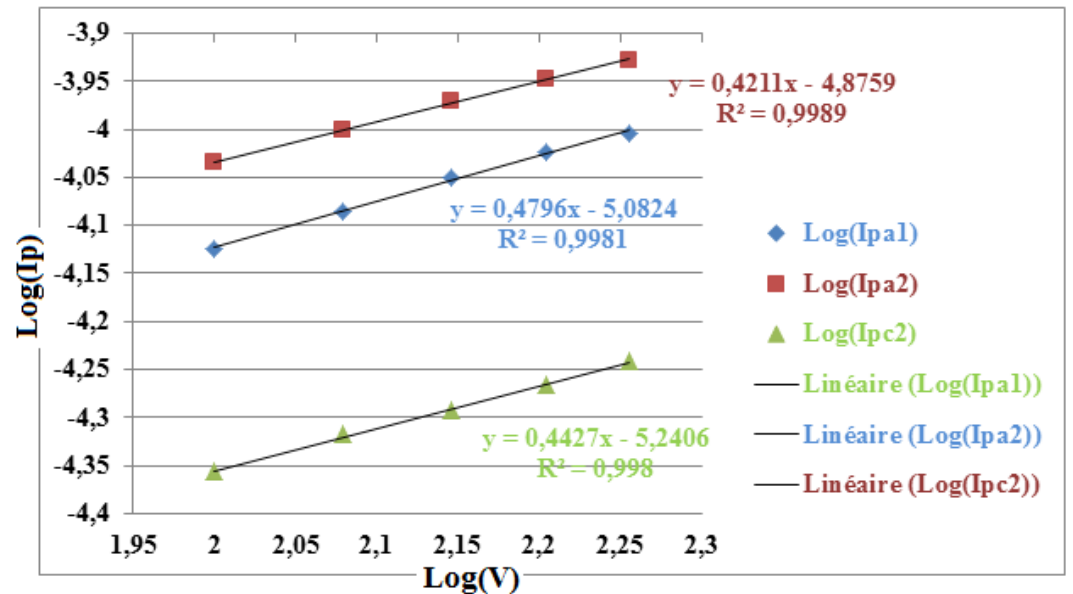

Figure 3: $\log (\mathrm{Ip})=\mathrm{f}(\log \mathrm{V})$ 


\subsection{Crystal structures of complexes}

The nickel(II) complex crystallizes in the orthorhombic space group Pbca. A perspective view of the complex structure is shown in Figure4 and main bond lengths and angles are listed in Table 2. The X-ray structure determination reveals that the complex consists of a discrete centrosymmetric mononuclear unit $\left[\mathrm{Ni}(\mathrm{HL})_{2}\right]$. The potential heptadentate ligand $\mathrm{H}_{2} \mathrm{~L}$ acts like a bidentate monodeprotonated ligand with the thiophenyl groups and one of the thiohydrazonic moieties remaining uncoordinated. The nickel(II) ion is linked to two molecules ligand by one imino nitrogen atom $\left(\mathrm{N} 1, \mathrm{~N}^{\mathrm{i}}\right)$ and one sulfur atom, in his thiolato form, $\left(\mathrm{S} 3, \mathrm{~S} 3^{\mathrm{i}}\right)$ per each molecule ligand $(\mathrm{i}=-\mathrm{x}+1 ;-\mathrm{y} ;-\mathrm{z}+1)$, resulting in square planar geometry. The square planar coordination geometry is almost regular in the $\mathrm{Ni}(\mathrm{II})$ complex. The four bond angles around the metal are all close to $90^{\circ}$. The bite angles corresponding to the formation of the five-membered rings (NiSCNN) slightly contracted with a value of $86.17(8)^{\circ}$ while the others are slightly enlarged to $93.83(8)^{\circ}$.This low flatness deviation is attested by the trans angles $\mathrm{N} 1-\mathrm{Ni}-\mathrm{N} 1^{i}$ and $\mathrm{S} 3-\mathrm{Ni}-\mathrm{S} 3^{\mathrm{i}}$ which are $180(1)^{\circ}$ [24]. Inspection of the bond lengths indicates that the ligand is coordinated to the $\mathrm{Ni}(\mathrm{II})$ ions in his thiolato form. Indeed the bonds length C11-S3 with 1.724(4) $\AA$ value is consistence with a simple bond [22]. Thevalues of bond lengths C5-N4 (1.281(5) $\AA$ )and (C6-N1 (1.300(4) $\mathrm{A})$ indicate a double bonds character [25].The $\mathrm{Ni}-\mathrm{S}$ and $\mathrm{Ni}-\mathrm{N}$ bond lengths values $[2.1699(8) \AA$ and $1.913(3) \AA]$ are comparable to those found for the corresponding distance [2.1766(7) and $1.908(3)]$ in the tetracoordinated square planar complex $\left[\mathrm{Ni}(\mathrm{L})_{2}(\right.$ were $\mathrm{HL}=$ benzyl-3-(3-hydroxyphenyl methyl ethylene)hydrazine carbodithioate))[26].

Table-2. Selected bond distances $[\AA]$ and angles $[\mathrm{deg}]$ for the $\mathrm{Ni}^{\mathrm{iI}}$ and $\mathrm{Zn}{ }^{\mathrm{II}}$ complexes.

\begin{tabular}{|l|l|l|l|}
\hline Ni1-N1 & $1.913(3)$ & Zn1-N8 & $2.036(4)$ \\
\hline Ni1-S3 & $2.1699(8)$ & Zn1-N4 & $2.066(5)$ \\
\hline C1-S1 & $1.705(6)$ & Zn1-S5 & $2.2634(19)$ \\
\hline C4-S1 & $1.714(4)$ & Zn1-S2 & $2.2815(17)$ \\
\hline N2-N1 & $1.386(4)$ & S2-C6 & $1.739(6)$ \\
\hline N1-C6 & $1.300(4)$ & S5-C17 & $1.745(6)$ \\
\hline C2-C1 & $1.335(7)$ & N1-C5 & $1.263(7)$ \\
\hline S2-C7 & $1.712(4)$ & N1-N2 & $1.364(7)$ \\
\hline S2-C10 & $1.702(4)$ & N3-N4 & $1.379(6)$ \\
\hline N2-C11 & $1.299(4)$ & N4-C7 & $1.291(8)$ \\
\hline N4-N3 & $1.366(4)$ & N2-C6 & $1.367(7)$ \\
\hline N3-C11 & $1.349(5)$ & N3-C6 & $1.307(7)$ \\
\hline C11-S3 & $1.724(4)$ & N8-Zn1-N4 & $121.0(2)$ \\
\hline C5-N4 & $1.281(5)$ & N8-Zn1-S5 & $86.76(14)$ \\
\hline S3-Ni1-S3 & $180.0(1)$ & N4-Zn1-S5 & $114.42(15)$ \\
\hline N1-Ni1-N1 & $180.0(1)$ & N8-Zn1-S2 & $114.26(13)$ \\
\hline N1-Ni1-S3 & $86.17(8)$ & N4-Zn1-S2 & $86.05(13)$ \\
\hline N1-Ni1-S3 & $93.83(8)$ & S5-Zn1-S2 & $138.44(9)$ \\
\hline
\end{tabular}

Table-3. Hydrogen bonds for the $\mathrm{Ni}^{\mathrm{II}}$ complex $[\AA$ and deg]

\begin{tabular}{|l|l|l|l|l|}
\hline $\mathrm{D}-\mathrm{H} \cdots \mathrm{A}$ & $\mathrm{D}-\mathrm{H}$ & $\mathrm{H} \cdots \mathrm{A}$ & $\mathrm{D} \cdots \mathrm{A}$ & $\mathrm{D}-\mathrm{H} \cdots \mathrm{A}$ \\
\hline $\mathrm{N} 2-\mathrm{H} 2 \mathrm{~N} \cdots \mathrm{O} 1 \mathrm{i}$ & $0.91(2)$ & $2.01(4)$ & $2.868(8)$ & $156(7)$ \\
\hline N6-H6N $\cdots \mathrm{O} 2 \mathrm{ii}$ & $0.91(2)$ & $1.93(3)$ & $2.819(10)$ & $165(7)$ \\
\hline
\end{tabular}

Symmetry codes: (i) $-\mathrm{x}+2, \mathrm{y}+1 / 2,-\mathrm{z}+3$; (ii) $-\mathrm{x}+2, \mathrm{y}-1 / 2,-\mathrm{z}+2$.

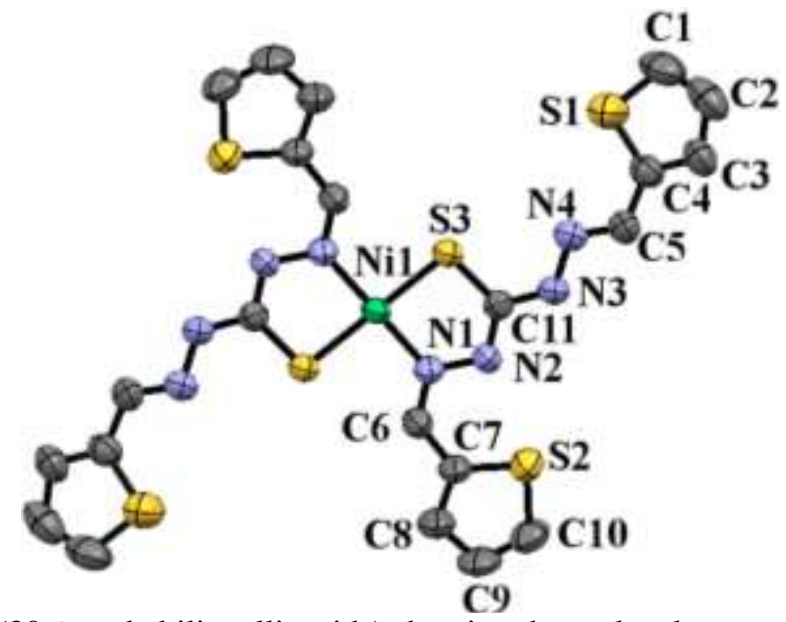

Figure 4:ORTEP plot (30\% probability ellipsoids) showing the molecule structure of the $\mathrm{Ni}^{\mathrm{II}}$ complex. 


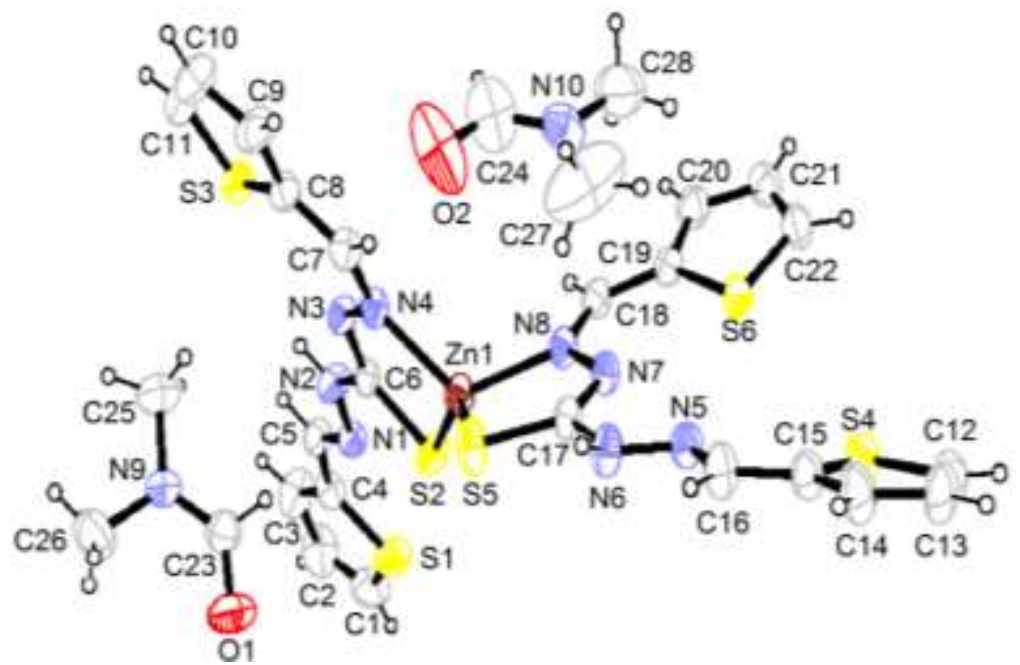

(a)

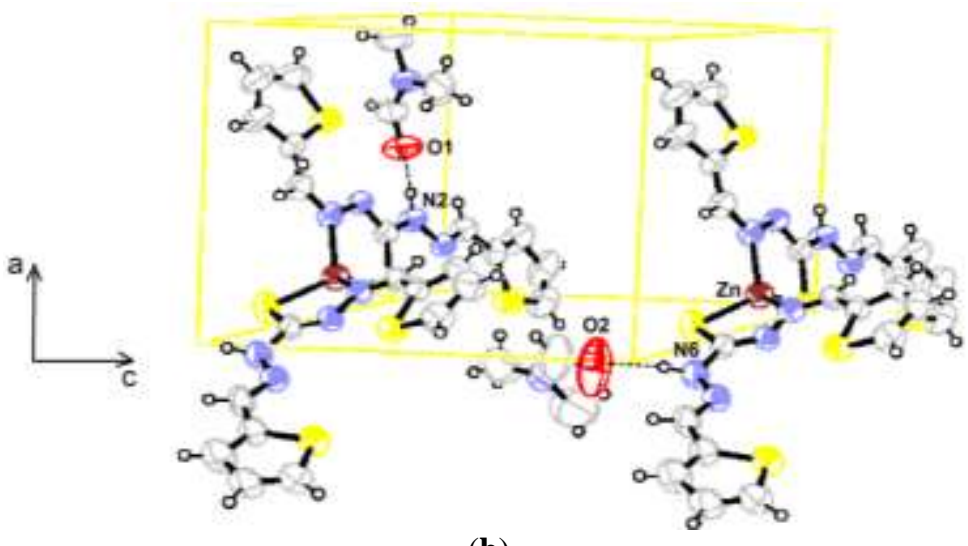

(b)

Figure 5:(a) ORTEP plot (30\% probability ellipsoids) showing the molecule structure of the $\mathrm{Zn}^{\mathrm{II}}$ complex. (b)The Crystal packing of the $\mathrm{Zn}{ }^{\mathrm{II}}$ complex with hydrogen bonds.

The zinc(II) complex crystallizes in the monoclinic space group $P_{2_{1}}$. The coordination of the thiocarbonohydrazone to $\mathrm{Zn}^{\mathrm{II}}$ results in the formation of two five membered ( $\mathrm{ZnSCNN}$ ) chelating rings. The following bonds C6-N2, C17-N7which are simple in character in the uncoordinated ligand molecule are altered in the complex and become double bond character with bond lengths of 1.307(6) $\AA$ and 1.292(7) $\AA$ respectively. The bond C6-S2 and C17-S5 which were double in character become a simple bond with values length of $1.745(6) \AA$ and 1.739(6) $\AA$ respectively. These facts are indicative of deprotonation of the N2-H and N7-H resulting in thio iminolisation of the ligand upon coordination. The title compound crystallizes in the monoclinic space group of $\mathrm{P}_{21}$ and Figure 5 depicts its mononuclearstructure. The $\mathrm{Zn}$ (II) center of the molecule complex is tetracoordinated. Two molecules ligands are coordinated to the $\mathrm{Zn}^{\mathrm{II}}$ ion. Each molecule ligand provides one nitrogen atom from hydrazone and one $S$ atom from the thiocabono moieties which constitute the severely distorted tetrahedral environment around the $\mathrm{Zn}$ center. The dihedral angle between the $\mathrm{ZnN}_{2}$ and $\mathrm{ZnS}_{2}$ planes is $73.03(13)^{\circ}$. The severely distorted tetrahedral geometry can be indicated by the bond angles subtended at $\mathrm{Zn}$ : $\mathrm{N}-\mathrm{Zn}-\mathrm{N}=121.0(2)^{\circ}, \mathrm{S}-\mathrm{Zn}-\mathrm{S}=138.44(9)^{\circ}$ and $\mathrm{S}-\mathrm{Zn}-\mathrm{N}$ in the range of 86.05(13)-114.42(15) ${ }^{\circ}$. The $\mathrm{Zn}-\mathrm{S}$ bond lengths values [2.2634(19) $\AA$ and 2.2815(17) $\AA$ ] are comparable to those found for the corresponding distance $[2.3117(6) \AA]$ in the tetracoordinated complex $\left[\mathrm{Zn}\left(5-\mathrm{CF}_{3} \mathrm{pyS}\right)_{2}(\right.$ bipy $\left.)\right]$ [27]. The $\mathrm{Zn}-\mathrm{N}$ bond distances [2.036(4) and 2.066(5) $\AA$ ] are essentially the same as those found in zinc complexes with hydrazone ligands [2.113(2) $\AA][28]$. The zinc and sulfur atoms as well as the zinc and the nitrogen atoms are rigorously coplanar for the $\left(\mathrm{ZnS}_{2}\right)$ and $\left(\mathrm{ZnN}_{2}\right)$. In this compound, there is hydrogen bonding involving the $\mathrm{NH}$ of the hydrazonic moieties of the ligand molecules [N2 and N6] and the oxygen atoms of the uncoordinated dmf molecules [O1 and O2] (Table 2) 


\section{Conclusion}

Thiocarbonohydrazide derivatives, with thiophenyl ring showed variety of modes coordination in the $\mathrm{Ni}^{\mathrm{II}}$ and $\mathrm{Zn}{ }^{\mathrm{II}}$ complexes which are prepared and characterized by elemental analys is, magnetic moment, molar conductivity, IR, UV-Vis and X-ray diffraction techniques. It is observed that the Nickel complex is diamagnetic while the zinc complex is paramagnetic. The complexes are non-ionic electrolyte. In both structure the ligand $\mathrm{H}_{2}$ Lacts as bidentate ligand through thiolato $\mathrm{S}$ and azomethine $\mathrm{N}$ atoms. Considering the magnetic moment, infrared spectra and the electronic spectrum data for $\mathrm{Ni}(\mathrm{II})$ complex, square planar geometry is proposed for the $\mathrm{Ni}(\mathrm{II})$ complex. The $\mathrm{Zn}$ (II) complex shows tetrahedral geometry. These observations are confirmed by X-ray diffraction studies.

\section{SupplementalData.}

CCDC 1055807 and 1055808 contains the supplementary crystallographic data for the complexes. These data can be obtained free of charge via http://www.ccdc.cam.ac.uk/conts/retrieving.html, or from the Cambridge Crystallographic Data Centre, 12 Union Road, Cambridge CB2 1EZ, UK; fax: (+44) 1223-336-033; or e-mail: deposit@ccdc.cam.ac.uk.

\section{References}

[1]. S. Biswas, S. Sarkar, I.M. Steele, S. Sarkar, G. Mostafa, B. B. Bhaumik, K. Dey, Two-dimensional supramolecular assembly of phenylmercury(II) and cadmium(II) complexes with a tridentate thiohydrazone NNS donor ligand: Synthesis, coordination behavior and crystal structure, Polyhedron,2007, 26, 5061-5068.

[2]. S. Biswas, G. Mostafa, I. M. Steele, S. Sarkar, K. Dey, Synthesis, crystal structures and luminescent properties of phenylmercury(II) complexes with thiohydrazone ligands having weak $\mathrm{Hg} \cdots \pi$ and $\mathrm{Hg} \cdots \mathrm{Hg}$ interactions, Polyhedron, 2009, 28, 1010-1016.

[3]. A. D. Naik, S. M. Annigeri, U. B. Gangadharmath, V. K. Revankar, V. B. Mahale, The stereochemical diversity of a new SNONS binucleating ligand towards 3d metal ions, Spectrochim. Acta A,2002, 58, 1713-1719.

[4]. Y. Sun, J. A. Rogers, Inorganic Semiconductors for Flexible Electronics, Adv. Mater.,2007, 19, 1897-1916.

[5]. F. Yakuphanoglu, Photovoltaic properties of hybrid organic/inorganic semiconductor photodiode, Synth. Met., 2007, 157, 859-862.

[6]. S. Biswas, F. Dagdelen, Y. Aydogdu, K. Dey, Structural, electrical and optical properties of metal complexes of NNS donor ligand, Mater. Chem. Phys., 2011, 129, 1121-1125.

[7]. E. Franco, E. López-Torres, M. A. Mendiola, M. T. Sevilla, Synthesis, spectroscopic and cyclic voltammetry studies of copper(II) complexes with open chain, cyclic and a new macrocyclic thiosemicarbazones, Polyhedron,2000, 19, 441-451.

[8]. N. Manav, N. K. Kaushik, Preparation, spectral characterization, in vitro antitumor and thermal studies of new platinum(IV) and palladium(II) thiohydrazone complexes, Trans. Met. Chem., 2002, 27, 849-855.

[9]. A. Singh, M. K. Bharty, R. K. Dani, S. Singh, S. K. Kushawaha, N. K. Singh, Manganese(II) and zinc(II) complexes of 4-phenyl(2-methoxybenzoyl)3-thiosemicarbazide: Synthesis, spectral, structural characterization, thermal behavior and DFT study, Polyhedron,2014, 73, 98-109.

[10]. A. D. Naik, V. K. Revankar, Design, synthesis and physico-chemical investigation of a dinuclearzinc(II) complex with a novel 'end-off' compartmental ligand, J. Chem. Sci., 2001, 113, 285-290.

[11]. P. M. Haba, F. B. Tamboura, O. Diouf, M. Gaye, A. S. Sall, C. A. Baldé, C. Slebodnick, Preparation, spectroscopic studies and x-ray structure of homobinuclear lanthanide(III) complexes derived from 2,6-diformyl-4-chlorophénol-bis-(2'-hydroxy-benzoylhydrazone), Bull. Chem. Soc. Ethiop., 2006, 20, 45-54.

[12]. E. I. Thiam, A. H. Barry, A. Navaza, P. Retailleau,M. Gaye, A. S. Sall, Bis(benzohydrazide- $\square^{2}$ O,N')bis(nitrato- $\square$ O)copper(II), ActaCryst., 2009, E65, m1014.

[13]. C. H. Kane, I. E. Thiam, F. B. Tamboura, M. Gaye, P. Retailleau, Bis $\{2$-amino-2-oxo-N-[(1E)-1-(pyridin-2-yl- $\square$ N)ethylidene $]$ acetohydrazidato$\kappa^{2} \mathrm{~N}^{\prime}, \mathrm{O}^{1}$ \} nickel(II), ActaCryst., 2012, E68, m553.

[14]. A. Sy, M. Dieng, I. E. Thiam, M. Gaye, P. Retailleau, Dichlorido $\left\{N^{\prime}\right.$-[phenyl(pyridin-2-yl- $\square$ N)methylidene]isonicotinohydrazide- $\left.\square{ }^{2} N^{\prime}, O\right\}$ zinc, ActaCryst., 2013, E69, m108.

[15]. M. M. Sow, O. Diouf, M. Gaye, A. S. Sall, G. Castro, P. Pérez-Lourido, L. Valencia, A. Caneschi, L. Sorace, Sheets of Tetranuclear Ni(II) [2 $\times 2$ ] Square Grids Structure with Infinite Orthogonal Two-Dimensional Water-Chlorine Chains, Cryst. Growth Des.,2013, 13, $4172-4176$.

[16]. W. Huang, $\{\mu-1,5$-Bis[(E)-1-(2-pyridyl)ethylidene] carbonohydrazidato(1-) $\}$ bis[chloridomethanolcopper(II)] perchlorate, ActaCryst., 2009, E65, m1347.

[17]. Y. Song, Y.-F. Ji, M.-Y. Kang, Z.-L. Liu, Bis(2-amino-5-methyl-1,3,4-thiadiazole- $\square \mathrm{N}^{3}$ )dichloridocobalt(II), ActaCryst., 2012 , E68, m772.

[18]. SHELXTL version, An Integrated System for Solving and Refining Crystal Structures from Diffraction Data(Revision 5.1), Bruker AXS Ltd., WI, USA, 1997.

[19]. G. M. Sheldrick, SHELXTL-97 Program for the Refinement of Crystal Structures, University of Gottingen, Germany, 1997.

[20]. L. Farrugia, ORTEP-3 for Windows - a version of ORTEP-III with a Graphical User Interface (GUI),J. Appl. Cryst., 1997, 30, 565.

[21]. W. J. Geary, The use of conductivity measurements in organic solvents for the characterisation of coordination compounds, Coord. Chem. Rev., 1971, 7, 81-122.

[22]. R. Takjoo, R. Centore, Synthesis, X-ray structure, spectroscopic properties and DFT studies of some dithiocarbazate complexes of nickel(II), J. Mol. Struct., 2013, 1031, 180-185.

[23]. P. Zanello, Inorganic Electrochemistry: Theory, Practice and Application, The Royal Society of Chemistry, 2003.

[24]. S. Bag, P. K. Bhaumik, S. Jana, M. Das, P. Bhowmik, S. Chattopadhyay, Syntheses and characterizations of square planar nickel(II) complexes with pendant ligands: Examples of bi-dentate bonding modes of potentially tri- and tetra-dentate Schiff bases, Polyhedron, 2013, 65, 229-237.

[25]. M. Dieng, O. Diouf, M. Gaye, A. S. Sall, P. Perez-Lourido, L. Valencia, A. Caneschi, L. Sorace, Polynuclear nickel(II) complexes with salicylaldimine derivative ligands, Inorg. Chim. Acta,2013, 394, 741-746.

[26]. E. Zangrando, M. T. Islam, M. Al-Amin, A. A. Islam, M. C. Sheikh, M. T. H. Tarafder, R. Miyatake, R. Zahan, M. A. Hossain, Synthesis, characterization and bio-activity of nickel(II) and copper(II) complexes of a bidentate NS Schiff base of S-benzyl dithiocarbazate, Inorg. Chim. Acta,2015, 427, 278-284.

[27]. A. Sousa-Pedrares, J. Romero, J. A. García-Vázquez, M. L. Durán, I. Casanova, A. Sousa, Electrochemical synthesis and structural characterisation of zinc, cadmium and mercury complexes of heterocyclic bidentate ligands (N, S), Dalton Trans., 2003, 1379-1388.

[28]. B. Samanta, J. Chakraborty, S. Shit, S. R. Batten, P. Jensen, J. D. Masuda, S. Mitra, Synthesis, characterisation and crystal structures of a few coordination complexes of nickel(II), cobalt(III) and zinc(II) with N'-[(2-pyridyl)methylene]salicyloylhydrazone Schiff base, Inorg. Chim. Acta,2007, $360,2471-2484$ 